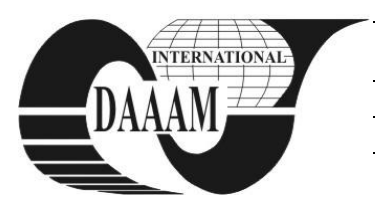

Annals of DAAAM for 2012 \& Proceedings of the 23rd International DAAAM Symposium, Volume 23, No.1, ISSN 2304-1382 ISBN 978-3-901509-91-9, CDROM version, Ed. B. Katalinic, Published by DAAAM International, Vienna, Austria, EU, 2012 Make Harmony between Technology and Nature, and Your Mind will Fly Free as a Bird Annals \& Proceedings of DAAAM International 2012

\title{
STUDIES CONCERNING THE DEPENDENCE OF THE CHARACTERISTIC ON THE SPEED OF DEFORMATION APPLIED TO METALLIC SHOCK ABSORBERS THROUGH PLASTIC DEFORMATION
}

\author{
OTLACAN, D[imitrie] D[anut] \& KAPOSTA, I[osif]
}

\begin{abstract}
The paper deals with the way in which certain metallic non-reversibly deformed parts could be employed in developing shock absorbers for railway vehicles. The study is based on experimental tests using the same type of parts deformed at speeds with ranging between $0.04 \mathrm{~mm} / \mathrm{s}$ and $5,800 \mathrm{~mm} / \mathrm{s}$. The aim of the present study is to determine whether there is a dependency, for the type of parts subjected to the tests, between the characteristics $F=f(d)$ measured in quasi-static regime and those measured in dynamic regime.

The study has applications in highlighting how the $F=f(d)$ of a structure, measured through tests concluded in static regime, can be used to evaluate the behavior of the same structure in dynamic regime.
\end{abstract}

Keywords: crash buffers, shock absorbers, railway vehicles, static regime, dynamic regime

\section{INTRODUCTION}

The studying of energy absorbing systems resulting from the accidental collision of rail vehicles has been a major concern of our research team in the last eight years. The results of the research work have lead to the design, testing and homologation/ certification of crash buffers for freight wagons and crash buffers for passenger carriages, using the same type of plastically deformed parts.

In the case of the crash buffers for freight wagons, the conditions that have to be met by their technical characteristics (the minimum value of the force at which plastic deformation starts, the average deformation force, the energy stored during the dynamic or static regime) are clearly defined by EU norms (EN 15551 and sheet UIC 573 ).

During the certification tests of crash buffers for freight wagons, the $\mathrm{F}=\mathrm{f}(\mathrm{d})$ chart has been determined both for the static and the dynamic regime.

\section{TESTS CONDUCTED IN STATIC REGIME}

Static tests included:

\section{A. Test with force F2}

This test has been performed on the "Test Bench for Buffers and Elastic Elements for Buffers and Draw Gears" code SIT-01.

A test with force $\mathrm{F} 2=0.5 \mathrm{MN}$ has been performed, on a buffer mounted on a doubly inclined support, so that the force point of application fully complies with UIC 526-1, pt. 2.1 and Annex 4. Fig. 1 shows how the F2 force has been applied.

Relevant buffer dimensions have been measured both before and after the test and it has been noted that they remained within the prescribed range of values.

Buffers have maintained their functional characteristics following the test. Fig. 2 illustrates the static diagrams after tests with force F2.

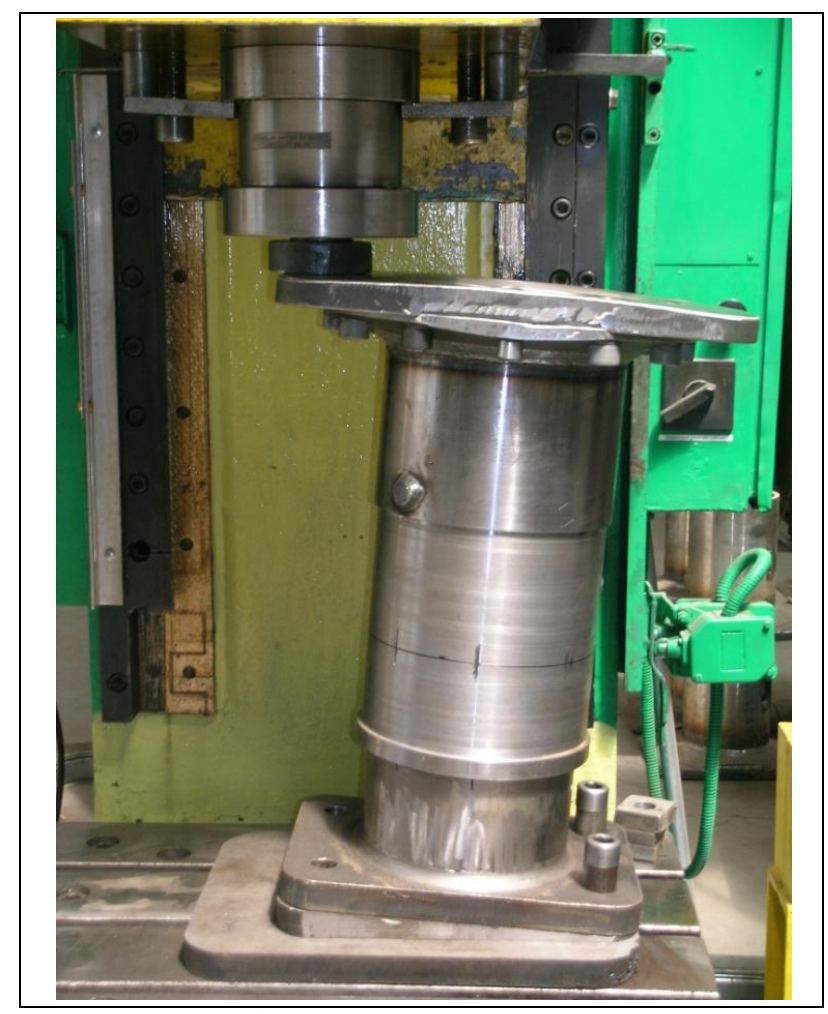

Fig. 1. Application of Force F1

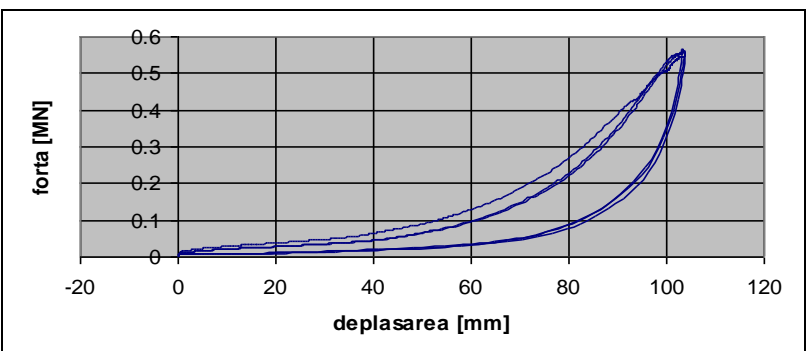

Fig. 2. Static Diagram Following Application of Force F2 


\section{B. Test with force F3 (Fig. 3)}

A test with force $\mathrm{F} 3=0.2 \mathrm{MN}$ has been performed, on a buffer horizontallyt mounted onto a device, similar to the way it would be mounted onto a wagon. The force has been applied using a prism positioned at $120^{\circ}, 50$ $\mathrm{mm}$ wide, placed $200 \mathrm{~mm}$ away from the surface where the buffer mounting plate rests. Fig. 4 illustrates the static diagram following application of force F3.

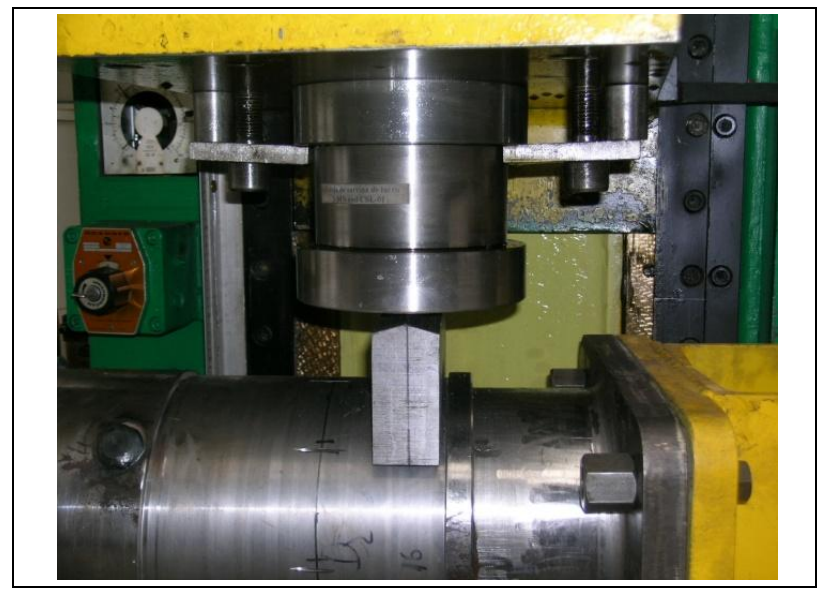

Fig. 3. Application of Force F3

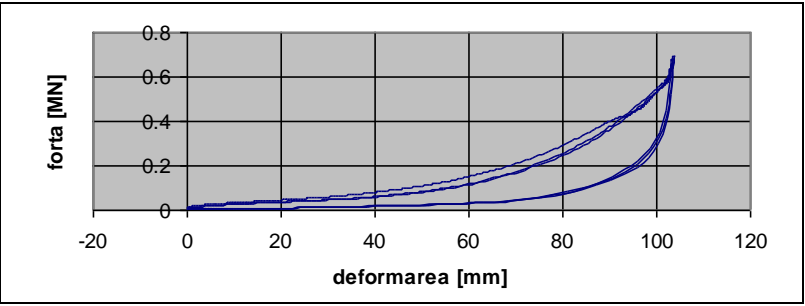

Fig. 4. Static Diagram Following Application of Force F3

\section{Determining the absorption capacity through elastic + plastic deformation}

The tests in static regime have been performed at deformation speeds of $0.03-0.06 \mathrm{~mm} / \mathrm{s}$. The static characteristic of the buffer equipped with A category TecsPak $^{R}$-MINER USA shock absorber is shown in Fig. 5. The defining elements of tests conducted in static regime are as follows:

- Total mechanical work stored through elastic + plastic deformation, $\mathrm{W}_{a}=416 \mathrm{~kJ}$

- Total mechanical work absorbed through elastic + plastic deformation, $\mathrm{W}_{e}=412 \mathrm{~kJ}$;

- Energy absorption coefficient $\left(\mathrm{W}_{e} / \mathrm{W}_{a}\right)=0.99$;

- $\quad$ Actual total travel $=300.4 \mathrm{~mm}$;

- Nominal total travel $=300 \pm 5 \mathrm{~mm}$;

- $\quad$ Energy stored via plastic deform., $\mathrm{Wa}_{p}=399.8 \mathrm{~kJ}$

- $\quad$ Energy stored via elastic deformation, $\mathrm{Wa}_{e}=16.2 \mathrm{~kJ}$;

- Average plastic deformation force, $\mathrm{F}_{\mathrm{med}}=2.03 \mathrm{MN}$;

- Plastic deformation initiating force, $\mathrm{F}_{\mathrm{i}}=2.08 \mathrm{MN}$;

- Maximum force, $\mathrm{F}_{\max }=2.71 \mathrm{MN}$.

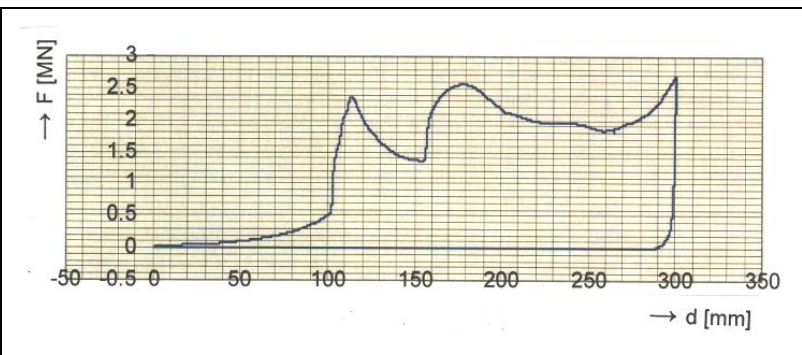

Fig. 5. Static Diagram Generated Through Plastic + Elastic Deformation

The photo in Fig. 6 shows from left to right:

- crash buffer prior to applying force F4 and raising static diagram through elastic + plastic deformation;

- measured crash buffer, equipped with A cat. TecsPak ${ }^{R}$ -MINER USA shock absorbers, after applying force F4 and raising static diagram through elastic + plastic deformation;

- crash buffer, equipped with A cat. Durel thermoplastic shock absorber after applying force $\mathrm{F} 4$ and raising static diagram through elastic + plastic deformation.

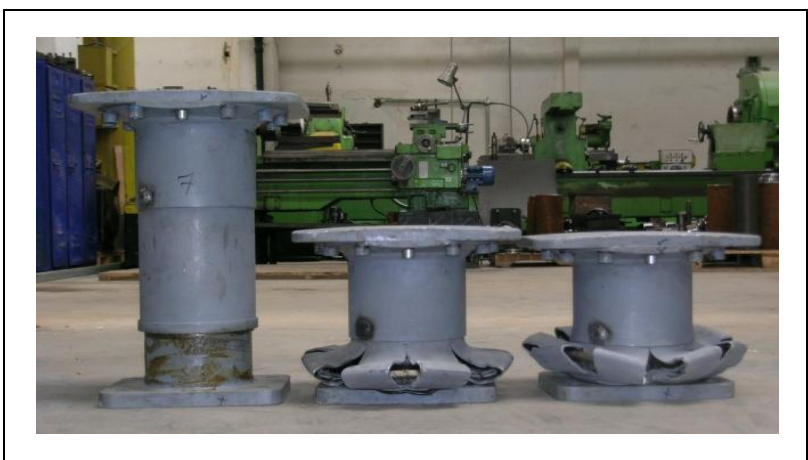

Fig. 6. Buffers Shown Before and After Elastic + Plastic Deformation

\section{TESTS CONDUCTED IN DYNAMIC REGIME}

Tests in dynamic regime have been conducted through impacting two wagons that were prepared for this purpose. One of the wagons is launched by a locomotive that brakes within a safety range so that it does not become a part of the impact, while the other wagon is stationed.

The stationed wagon (the wagon being impacted) is a gondola-type wagon using a draw gear with a force measurement device mounted onto it (see Fig. 7). The measurement device includes a $3 \mathrm{MN}$ load cell mounted within a doubly tubular chamber that transmits the force of compression to the draw gear.

The stationed wagon is also carrying a deformation measurement system, for the wagon that undergoes the test. Fig. 8 shows how the buffer and the measurement systems are mounted onto the wagon. The measurement transducers comprise a fixed part that is secured onto the front bar of the wagon and a mobile part that is mounted onto the buffer plate. 
1- pressure plate;

2- buffer mounting plate;

3- mounting and guiding device for the load cell; 
- Energy stored through plastic deformation $\mathrm{We}_{p}=$ $395 \mathrm{~kJ}$

- Energy stored and absorbed through elastic deformation $\mathrm{W}_{s}=51 \mathrm{~kJ}$;

- Total mechanical work stored through elastic+ plastic deformation, $\mathrm{W}_{a}=437 \mathrm{~kJ}$

- Energy absorption coefficient $\mathrm{W}_{a} / \mathrm{W}_{e}=0.98$

- Actual total travel = $282 \mathrm{~mm}$;

- Actual travel of plastic deformation $=180 \mathrm{~mm}$;

- Nominal travel of plastic deformation $\mathrm{S}_{p}=195 \pm 5$ $\mathrm{mm}$;

- Average plastic deformation force, $\mathrm{Fd}=2.19 \mathrm{MN}$

- Plastic deformation initiating force, $\mathrm{Fi}>2.2 \mathrm{MN}$;

- Maximum force, $\mathrm{F}_{\text {max }}=2.84 \mathrm{MN}$;

Energy absorption capacity in dynamic regime, $\mathrm{W}_{d}$ :

$$
\mathrm{W}_{d}=\mathrm{W}_{s}+\mathrm{F}_{d} * \mathrm{~S}_{p}
$$

Where:

$\mathrm{W}_{d}=$ total energy absorption capacity

$\mathrm{W}_{s}=$ energy absorption capacity in elastic

phase, $\mathrm{W}_{s}=51,000 \mathrm{~J}$

$\mathrm{F}_{d}=$ average plastic deformation force in dynamic regime, $\mathrm{F}_{d}=2,190,000 \mathrm{~N}$

$\mathrm{S}_{p}=$ nominal plastic deformation travel determined in static regime, $\mathrm{S}_{p}=0.195 \mathrm{~m}$

Thus, it results:

$\mathrm{W}_{d}=51,000+2,190,000 * 0.195=478,050 \mathrm{~J}=478.050 \mathrm{~kJ}$

\section{DIFERENCES BETWEEN THE TWO TESTS}

Fig. 13 shows two overlapped charts, one generated following tests conducted in static regime and the other one generated in dynamic regime belonging to two buffers made after the same manufacturing Fig.13

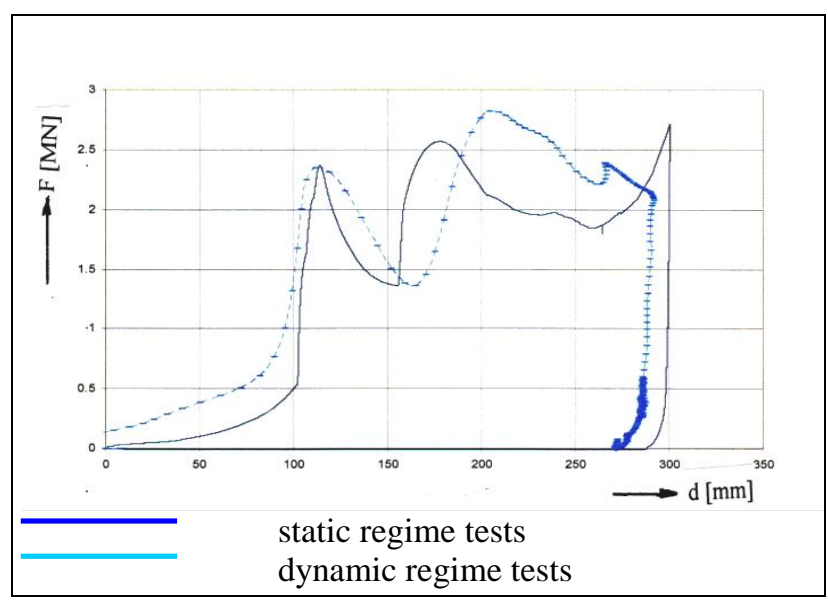

Fig. 13. Comparison Between $\mathrm{F}=\mathrm{f}(\mathrm{d})$ Build in Static, resp. Dynamic Regime

\section{CONCLUSIONS}

The comparison of these two charts provides the following conclusions:

1. During the tests conducted in dynamic regime the stored energy in the elastic deformation phase is $150 \%$ bigger that the energy stored in the elastic deformation phase in the static regime. The shock absorbers used are TecsPak made in the USA.

2. The difference between the energy stored in the plastic deformation phase in static regime and the energy stored in the plastic deformation phase in dynamic regime does not exceed $10 \%$.

3. The difference between the maximum force in the plastic deformation phase in static regime and the maximum force in the same phase in dynamic regime is not more than $10 \%$.

The analysis of the above mentioned results has made the authors conclude that in the plastic deformation phase of the buffers there are no significant differences between the $F=f(d)$ characteristics in the case of tests conducted in static or dynamic regime.

Based on the experience gained so far, it can be considered that the small differences registered are due to manufacturing allowances of the deformed parts and to the actual characteristics of the steel charges out of which the half products have been manufactured.

If these conclusions are extrapolated to other metallic structures (which require these kind of studies in static and dynamic regime), it can be admitted that the evaluation of the behavior of these structures in dynamic regime can be performed in a satisfactory manner (depending on the importance of the respective structure, in the modeling and dimensioning phase of the crash structure) only if the results obtained in the static regime are taken into consideration.

\section{REFERENCES}

[1] Dixon, J. (1998) The shock absorber handbook, Society of Automotive Engineers, Warendale, $\mathrm{Pa}$.

[2] EN 15551 Railway applications - Railway rolling stock - Buffers

[3] Otlacan D. et al (2007) Contributions to the improvement of the dynamic characteristics of the hydrostatic springs, Proc. 18th DAAAM International Symposium, Zadar, 533-534

[4] Otlacan D. et al (2008) Contributions to the hydrostatic buffers for railways vehicles, Proc. 19th DAAAM International Symposium, Trnava, 533-534

[5] UIC 526-1 (1998) Wagons. Tampons a course de $105 \mathrm{~mm}$.

[6] UIC 573 Ed. 7 (2007) Technical Conditions For The Construction Of Tank Wagons.

[7] Tests Report no. 014/2009 - "Static Tests Upon Crash Buffer Category A", project IST-04.00.00 Innova Systems \& Technologies.

[8] Tests Report no. 016/2009 - "Dynamic Tests Upon Crash Buffer Category A", project IST-04.00.00 Innova Systems \& Technologies 